\title{
Effect of aging mode on the IMC growth of SAC(305)/Cu solder joints during aging
}

\author{
QU Min ${ }^{a}$, CAO Tian Ze ${ }^{b}$, CUI Yanc, LIU Feng Bin ${ }^{d}$, JIAO Zhi Wei $^{\mathrm{e}}$, LIU Yuan $^{f}$
}

School of Mechanical and Materials Engineering,

\author{
North China University of Technology, Beijing 100144, China \\ aminqu@ncut.edu.cn, 'lionalice@sina.com, 'cuiyan@ncut.edu.cn, \\ dfbliu@ncut.edu.cn, 'zwjjzw@ncut.edu.cn, 'liuyuan@ncut.edu.cn
}

\begin{abstract}
Keywords: Sn-3.0Ag-0.5Cu solder, aging mode, intermetallic compound, thickness
Abstract. Two different aging modes of continuous aging and interval aging were adopted to investigate the intermetallic compound (IMC) growth between Sn-3.0Ag-0.5Cu (SAC(305) )solder and $\mathrm{Cu}$ substrate. The morphologies of IMC layer are different during two different aging modes, and there is only one phase $\left(\mathrm{Cu}_{6} \mathrm{Sn}_{5}\right.$ phase $)$ form during interval aging. Despite the different morphologies, the growth of IMC layers both follow diffusion control mode during two different aging styles, and the growth rate of IMC layer is slowlier over interval aging than that over continuous aging. In addition, it is illuminated the phenomenon of no $\mathrm{Cu}_{3} \mathrm{Sn}$ form during interval aging, this can be mainly explained by interval aging mode and diffusion growth mode, the free energy of system is not high enough to overcome the kinetic energy barrier and make the $\mathrm{Cu}_{6} \mathrm{Sn}_{5}$ phase change into $\mathrm{Cu}_{3} \mathrm{Sn}$. In a word, the reliability of $\mathrm{SAC}(305) / \mathrm{Cu}$ solder joints can be improved during interval aging.
\end{abstract}

\section{Introduction}

Fast miniaturization of electronic products results in rapid shrinkage of IC packages and swiftly increasing number of input/output pins, which require solder interconnects that are employed in BGA, flip-chip packaging, 3D staking and wafer level packaging to be further downsized. Solder joints mainly used as interconnects, are now facing great challenges on the gradual downsizing of the ball size due to the extreme shrinkage ${ }^{[1]}$. Solder paste determines the joint strength and thermal, mechanical, and electrical behaviors of various electronic packages and substrates ${ }^{[2]}$. Pb-free solder paste is commonly used in electronic packaging industries to eradicate the harmful effects of $\mathrm{Pb}$ on human health and the ecosystem ${ }^{[3]}$. In recent literature, a lot of research work focused on the application of different lead -free solders in surface mount application (SMT), including Sn-Cu and $\mathrm{Sn}-\mathrm{Zn}, \mathrm{Sn}-\mathrm{Ag}$. However, there are some shortcomings need to be overcome. ie, poor wettability, poor mechanical properties, high melting point, high cost, excessive growth of interfacial compounds, easy oxidation as compared to $\mathrm{Sn}-\mathrm{Pb}$ eutectic alloys.

To improve the microstructure and properties of lead-free solders, the alloying element was added to lead-free solders. $\mathrm{Li}^{[4]}$ investigated the size of $\mathrm{Ag}$ nanoparticles on the microstructure and mechanical properties of $\mathrm{Sn} 58 \mathrm{Bi}-\mathrm{Ag}$ composite solders, results showed that Ag played a positive role in improving the microstructure and mechanical properties of Sn58Bi solder and the extent of the improvement differed with the size of the doped Ag particles. Qiu ${ }^{[5]}$ researched the formation of intermetallic reaction layers and their influence on shear strength between the $\mathrm{Zn}-\mathrm{Sn}-\mathrm{Cu}-\mathrm{Bi}$ (ZSCB) and $\mathrm{Cu}$ substrate during the liquid state reaction, results showed that reliable solder joints could be obtained at $450 \square$ after $15-30$ s of wetting. Çadırl ${ }^{[6]}$ studied the effect of temperature gradient and growth rate on the mechanical, electrical and thermal properties of the $\mathrm{Sn}-\mathrm{Zn}$-Bi eutectic alloy, result showed that the melting temperature of Sn-23 wt.\% Bi-5 wt.\% Zn alloy was detected to be $448.14 \mathrm{~K}$. $\mathrm{Hu}^{[7]}$ investigated the interfacial reactions between $\mathrm{Cu}$ and $\mathrm{Sn}-3.0 \mathrm{Ag}-0.5 \mathrm{Cu}$ (SAC305) solder reflowed under various cooling rates, the results verify that the Cu6Sn5 grains coarsened linearly with cubic root of aging time. Nishikawa ${ }^{[8]}$ researched the formation and growth of an intermetallic compound (IMC) layer at the $\mathrm{Sn}-\mathrm{Ag}-\mathrm{Cu}$ solder/Cu interface after laser soldering and during isothermal aging, result showed that a relatively thin IMC layer is formed at the interface of the joints soldered by the laser process. Among these solders, $\mathrm{Sn}-\mathrm{Ag}-\mathrm{Cu}$ solder, especially $\mathrm{Sn}-3.0 \mathrm{Ag}-0.5 \mathrm{Cu}$ 
(SAC305) solder has been selected as the best replacement material for $\mathrm{Sn}-\mathrm{Pb}$ solder in electronic assemblies currently.

Generally speaking, the electronic products usually don't service continuously. Actually, some of the electronic products service discontinuously, they follow the working mode like this: workrest-work, just as our humankind. However, up to now, researches have focused on the continuously isothermal aging on the solder joints studies. Usually, during continuously isothermal aging, some Kirkendall voids would form in the $\mathrm{Cu}_{3} \mathrm{Sn}$ layer with aging time increasing. It is worth noting that the number of Kirkendall voids will increase with increasing aging time, leading to the formation of micro-crack, which is detrimental to the reliability of solder joint. Hence, $\mathrm{Cu}_{3} \mathrm{Sn}$ is unfavorable for the reliability of solder joints, it's better to avoid the appearance of $\mathrm{Cu}_{3} \mathrm{Sn}$ during aging.

Based on the above condition, in this paper, we adopt the interval aging mode to study the IMC growth of SAC305 solder in order to simulate the real application environment. Moreover, we also study the continuous aging mode of SAC305 solder under the same condition so as to compare the growth behavior and growth kinetics of IMC layer.

\section{Experimental procedure}

The commercial copper plates with dimensions of $15 \mathrm{~mm} \times 15 \mathrm{~mm} \times 3 \mathrm{~mm}$ were used as the substrates in this study. SAC(305) solder paste was placed on the preprocessed substrates with a diameter of 5 $\mathrm{mm}$. Further, solder joints were formed with a F4N infrared reflow furnace. The specimens were reflowed at above liquidus temperature but the peak temperature wasn't beyond $260^{\circ} \mathrm{C}$ for $250 \mathrm{~s}$.

After reflowing, the prepared solder joints were performed isothermal aging experiment in an vacuum drying oven at $150^{\circ} \mathrm{C}$ for $48 \mathrm{~h}, 96 \mathrm{~h}, 144 \mathrm{~h}, 192 \mathrm{~h}$, and $240 \mathrm{~h}$ both continuous aging and interval aging, respectively. Most importantly, the interval aging was adopted in our study, namely, the solder joints were aged continuously for 17 hours and then stopped aging for 7 hours, the operation was then repeat until the total time reached $48 \mathrm{~h}, 96 \mathrm{~h}, 144 \mathrm{~h}, 192 \mathrm{~h}$, and $240 \mathrm{~h}$, respectively.

In order to investigate the formation and evolution of interfacial IMCs, specimens were sectioned perpendicularly to the solder/copper interface of the solder joint and mounted in Klarmount. The interfacial morphologies of solder joints were observed by a Scanning Electron Microscope (SEM, ZEISS-EVO18) equipped with an Energy Dispersive X-ray Spectrometer (EDS).

Considering the reliable and repeatable data of the mean thickness of IMCs layer, three solder joint samples for each reflow cycle and aging time were used, SEM image analysis software was then employed to digitally measure the areas of each sample's IMCs layers from left side to right side. The thickness of IMCs layer is determined by the area of the IMCs layer dividing its length, and the mean thickness of IMCs layers was then calculated by averaging the data.

\section{Results and Discussion}

Microstructure observation of interfacial IMC layers. Fig. 1 shows the cross-sectional SEM images of interface morphologies of $\mathrm{SAC}(305) / \mathrm{Cu}$ solder joints during interval aging for various times. As can be seen in Fig.1(a), the $\mathrm{IMC} \mathrm{Cu}_{6} \mathrm{Sn}_{5}$ layer is rounded scallop shape. some wicker-shape of $\mathrm{Cu}_{6} \mathrm{Sn}_{5}$ are formed in $\mathrm{Sn}$ matrix, and the $\mathrm{Ag}_{3} \mathrm{Sn}$, white small particles, uniformly dispersed in $\mathrm{Sn}$ matrix. In addition, it is shown that the IMC layer is only $\mathrm{Cu}_{6} \mathrm{Sn}_{5}$ phase, there is no dark gray $\mathrm{Cu}_{3} \mathrm{Sn}$ layer appeared in Fig.1(a). With aging time increasing, there is still no $\mathrm{Cu}_{3} \mathrm{Sn}$ layer appeared even the aging time reaches to $240 \mathrm{~h}$, moreover, the IMC layer grows thicker and the shape of $\mathrm{Cu}_{6} \mathrm{Sn}_{5} \mathrm{changes}$ from rounded scallop shape to elongated shape with an increase in the aspect ratio gradually as shown in Fig.1(d) and Fig.1 (e).

Due to $\mathrm{Cu}_{3} \mathrm{Sn}$ phase doesn't appear during the interval aging, the probable factors induce the result maybe reflow time, reflow temperature, solder materials, aging time, aging temperature or aging mode, et al. To demonstrate whether the result attribute to aging mode, we set an experiment with the same parameters in interval aging experiment expect aging mode. In contrast to interval aging, we adopt the continuous aging mode. The results are shown in Fig.2. It is found that the IMC layer is scallop shape with large gaps when the continuous aging time is $48 \mathrm{~h}$ as shown in Fig.2(a). As 
continuous aging time extended, the gap are gradually decreased. From Fig.2(a)-(e), it can be observed that the IMC layer changes from scallop shape to nearly layer shape, and the IMC layer grows thicker with continuous aging time increasing. Furthermore, it can be seen obviously that the IMC layer is composed of two layers, a light gray layer and a dark gray layer, according to the BSE imaging principle, it's know that they different color represent different phase, and they are $\mathrm{Cu}_{6} \mathrm{Sn}_{5}$ and $\mathrm{Cu}_{3} \mathrm{Sn}$ respectively. Therefore, $\mathrm{Cu}_{3} \mathrm{Sn}$ phase appears during continuous aging in Fig.2. However, it is noteworthy that $\mathrm{Cu}_{3} \mathrm{Sn}$ phase doesn't form during interval aging. Thus, compare Fig.1 and Fig.2, we discover that there are different phase in interfacial IMC layer during different aging mode, we can put forward that different aging mode affect the interfacial IMC layer of SAC(305)/Cu solder joints.
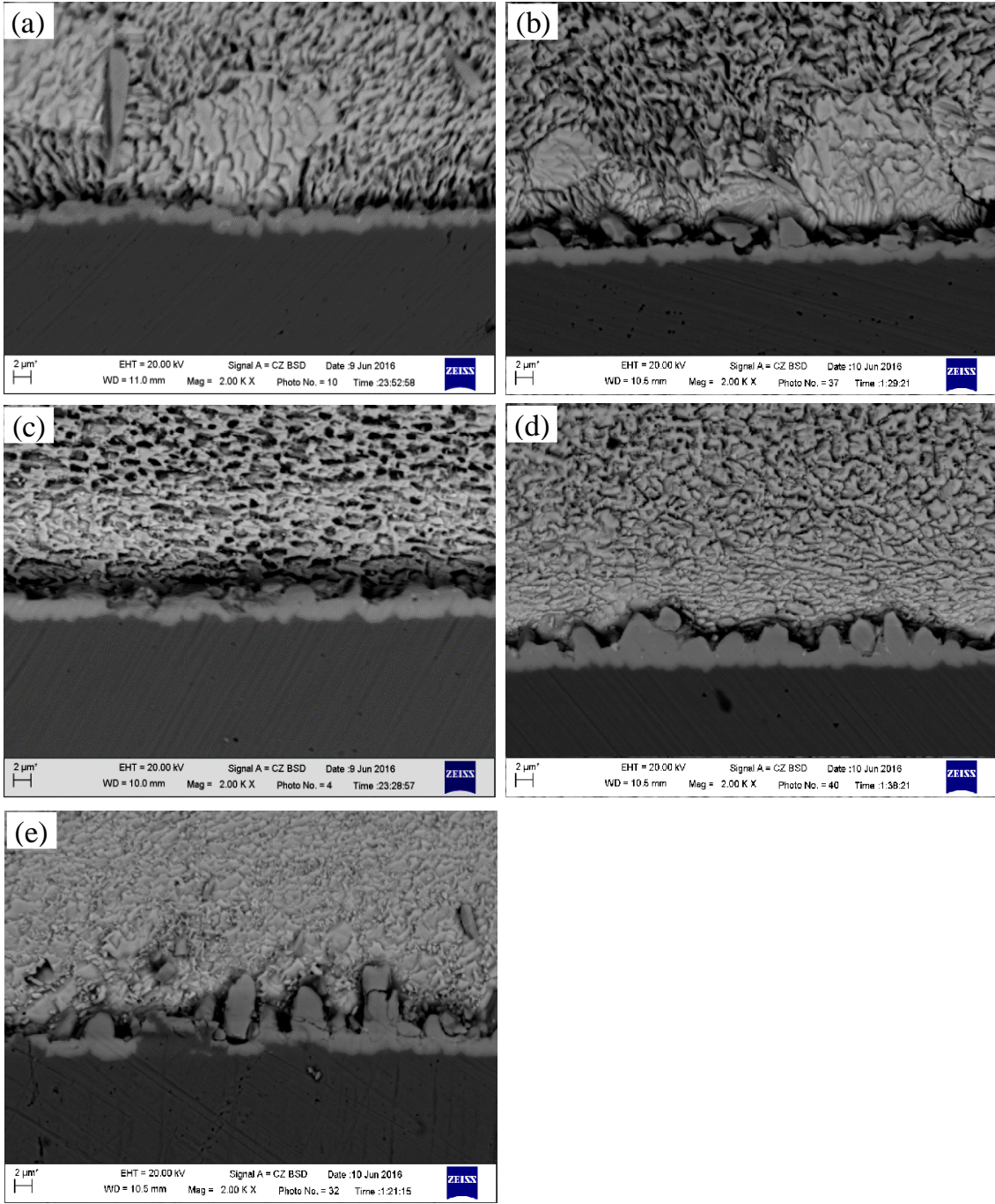

Fig.1 BSE images of cross-sectional view of $\mathrm{SAC}(305) / \mathrm{Cu}$ solder joints during interval aging for (a) $48 \mathrm{~h}$, (b) $96 \mathrm{~h}$, (c) $144 \mathrm{~h}$, (d) 192h, (e) 240h, respectively.

Growth kinetics of IMC layer. The thicknesses of IMC layer of the two different aging modes were measured to study their growth behavior. Generally, the thickness of IMC layer can be expressed by an power law equation ${ }^{[9]}$, proceeding as $X=X_{0}+k t^{n}$, where $X$ is the IMCs layer thickness after aging, $X_{0}$ is the initial thickness of IMCs layer after reflow soldering, $t$ is aging time, and $k$ is a constant about growth rate, $n$ is the time exponent. For continuous aging, $\mathrm{n}$ usually equals to 0.5 indicating that the growth rate is controlled by volume diffusion when the intermetallic growth follows parabolic growth kinetics. However, for interval aging, we're not sure whether the growth of IMC layer follows this equation, so we plot the thickness of the interfacial IMC layers as a function of square root of the aging time as shown in Fig.3. After linear regression, it is seen that the IMC layers thickness increases almost linearly over the aging time after both interval aging and continuous aging. This confirms that the growths of both IMC layers follow the parabolic growth kinetics. Accordingly, 
the IMC growth behavior of SAC(305) solder for both aging mode can be considered a diffusion control process.
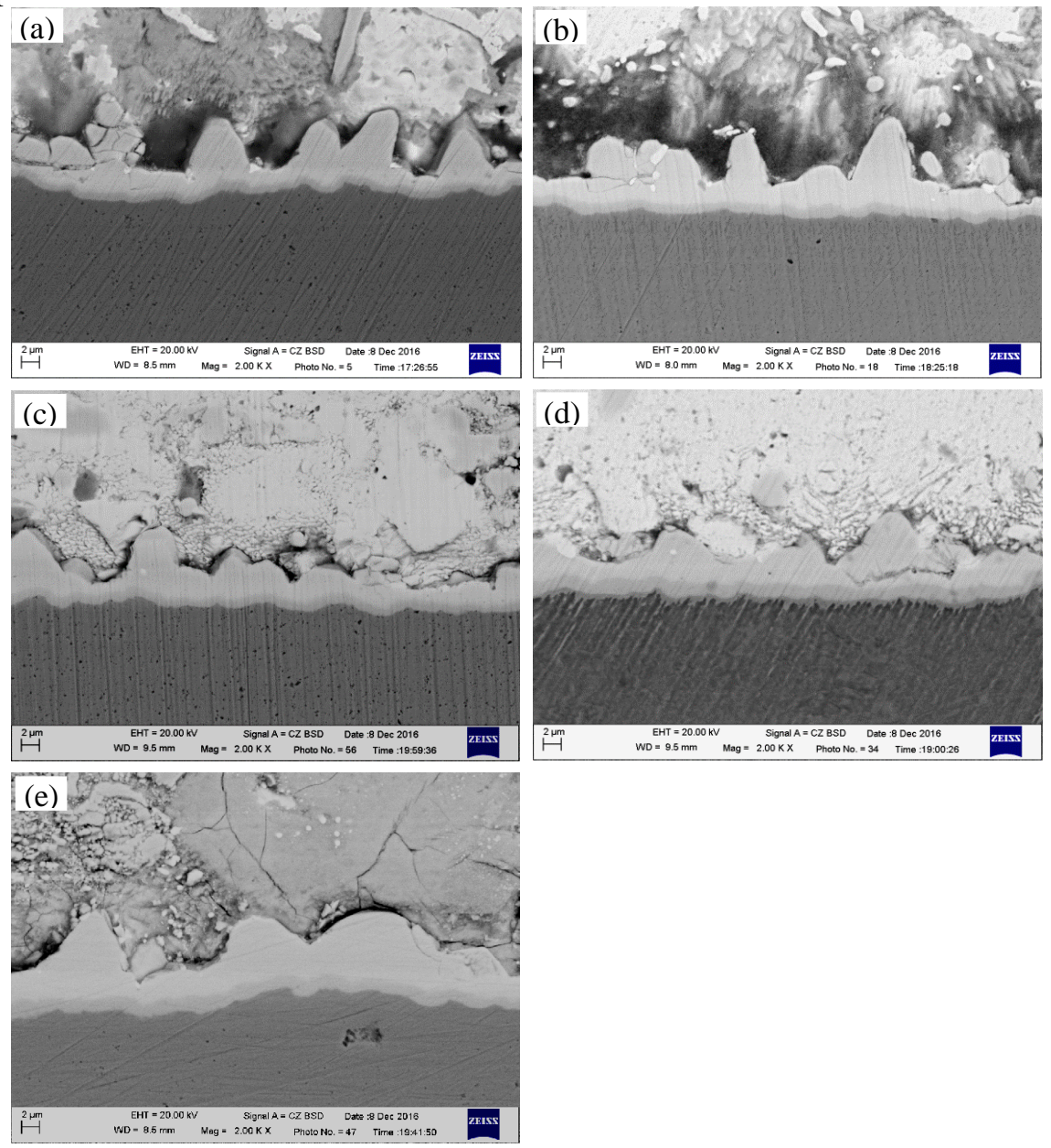

Fig.2 Backscattered SEM micrographs of SAC(305)/Cu solder joints during continuous aging for (a) 48h, (b) $96 \mathrm{~h}$, (c) $144 \mathrm{~h}$, (d) 192h, (e) 240h, respectively.

In present study, We have previously shown that $\mathrm{Cu}_{3} \mathrm{Sn}$ phase doesn't appear over interval aging process, due to the diffusion control mode of IMC growth and interval aging style, according to kinetics, the diffusion activation energy is not high enough to overcome the kinetic energy barrier and make the $\mathrm{Cu}_{6} \mathrm{Sn}_{5}$ phase change into $\mathrm{Cu}_{3} \mathrm{Sn}$. Hence, there is no $\mathrm{Cu}_{3} \mathrm{Sn}$ appeared and only $\mathrm{Cu}_{6} \mathrm{Sn}_{5}$ phase formed, consequently, the reliability of solder joints is improved.

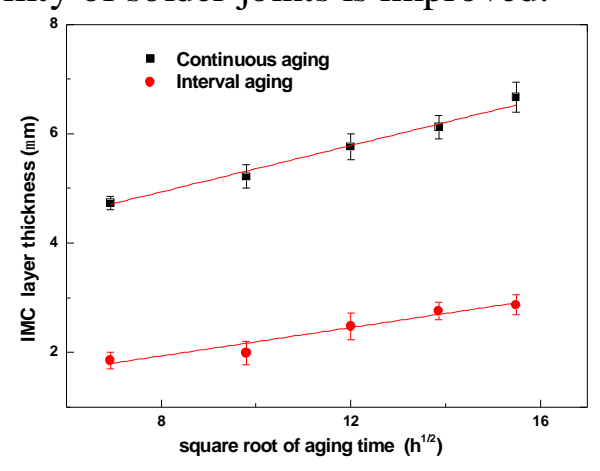

Fig.3 Interfacial IMC thickness of $\mathrm{SAC}(305) / \mathrm{Cu}$ solder joints with different aging time.

By linear regression, the growth kinetics equation after both interval aging and continuous aging can be expressed as $X=0.91+0.13 t^{1 / 2}$ and $X=3.24+0.21 t^{1 / 2}$, respectively. As previously shown that $k$ is a constant about growth rate, it is noticeable that the growth rate of IMC layer after interval aging is smaller than that over continuous aging. As a result, it is confirmed that the IMC layer grows slowlier over interval aging than that during continuous aging. In order to improve the solder joints reliability, usually an effective way is to suppress the growth of IMC layer due to its brittle phase. Hence, from 
this study, it can be concluded that the interval aging mode can effectively improve the solder joints reliability.

\section{Conclusions}

IMC growth of $\mathrm{SAC}(305) / \mathrm{Cu}$ solder joints was investigated during interval aging and continuous aging mode. It was found that IMC layers are different over two aging mode, and the IMC layer is formed from the only one phase $\left(\mathrm{Cu}_{6} \mathrm{Sn}_{5}\right.$ phase) during interval aging. Also, the IMC layer is thicker over continuous aging than over interval aging. Despite the different phase of IMC layer, the growth of IMC layers are both follow diffusion control mode during two different aging mode, and the growth rate over interval aging is slowlier than that over continuous aging. In addition, it was explained no $\mathrm{Cu}_{3} \mathrm{Sn}$ phase appears over interval aging, due to the diffusion control mode of IMC growth and interval aging style, the diffusion activation energy is not high enough to overcome the kinetic energy barrier and make the $\mathrm{Cu}_{6} \mathrm{Sn}_{5}$ phase change into $\mathrm{Cu}_{3} \mathrm{Sn}$. It could be concluded that the interval aging mode can effectively improve the solder joints reliability.

\section{Acknowledgments}

The authors would like to acknowledge the financial support provided by National Natural Science Foundation of China (NSFC) under grant No. 51604012 and 51575004, Foundation of Beijing outstanding talent training under grant No.2014000020124G010, and Natural Science Foundation of Beijing (NSFB) under grant No.3162010.

\section{References}

[1] S. Xu, Y. C. Chan, K.Zhang and K.C. Yung: J. Alloy.Comp. Vol. 595 (2014), p. 92

[2] S. Chellvarajoo and M.Z. Abdullah: Mater. Design Vol. 90 (2016) , p. 499

[3] L. Zhang and K.N. Tu: Mater. Sci. Eng.R Vol. 82 (2014), p. 1

[4] Y. Li and Y.C. Chan: J. Alloy.Comp. Vol. 645 (2015), p. 566

[5] F. Xing, J.Yao, J.W Liang and X.M. Qiu: J. Alloy.Comp. Vol. 649 (2015), p. 1053

[6] E. Çadırlı, U. Böyük, H. Kaya and N Maraşl1: J. Non-Cryst.Solids Vol.357 (2011), p. 876

[7] X. W.Hu, T. Xu, X.X. Jiang, Y.L. Li, Y. Liu andZ.X. Min: Applied Physics A Vol. (2016), p. 278

[8] H.Nishikawa and N. Iwata: J. Mater. Proc. Tech. Vol. 215 (2015), p.6

[9] P. L. Tu, Y. C. Chan, K. C. Hung and J. K. L. Lai: Script. Mater. Vol. 44 (2015), p. 317 